\title{
Role of physiotherapy in oral submucous fibrosis
}

\author{
Shaik Ali Hassan ${ }^{1 *}$, Sumit Bhateja ${ }^{2}$ \\ ${ }^{1}$ Dental Surgeon, ${ }^{2} \mathrm{HOD},{ }^{1,2}$ Manav Rachna Dental College, Faridabad, Haryana, India \\ *Corresponding Author: Shaik Ali Hassan \\ Email: alishaikhassan@gmail.com
}

\begin{abstract}
Oral submucous fibrosis is a chronic, progressive, high risk premalignant condition seen mostly in the Indian subcontinent. It is mostly linked to betel consumption as a causative factor. The primary problem with oral submucous fibrosis is the stiffness of the mouth or difficulty in mouth opening. This is treated with medication followed by the use of exercises of the mouth prescribed by a physiotherapist. However, the role of the physiotherapist is not well defined. This article attempts to describe the type and method of exercises which can be prescribed in the treatment of oral submucous fibrosis (OSMF).
\end{abstract}

Keywords: Physiotherapy, OSMF, Exercises.

\section{Introduction}

Pindborg et al. (1966) defined OSMF as an insidious and chronic disease that affects any part of the oral cavity and, sometimes, the pharynx. Although sometimes preceded and / or accompanied by vesicle formation, it is still associated with inflammation of the juxta epithelium. This reaction is followed by a fibrolastic change in the lamina propria, where epithelial atrophy leads to a stiffness of the oral mucosa that causes trismus and inability to eat. ${ }^{1}$ There can be a hearing problem due to eustachian tube effect. Worldwide estimate is of 2.5 million people affected with OSMF with most of the cases from the Indian subcontinent, especially southern India. ${ }^{2}$ Most important and potent cause for oral submucous fibrosis is the consumption of areca nut. ${ }^{3-5}$ The slaked lime releases alkaloids (arecoline, arecaidine, guvacine, and guvacoline) from the areca nut, giving a feeling of euphoria and well-being in the person consumed. ${ }^{6}$ In this condition there is mucosal rigidity and inability to open the mouth. There are 2 treatment modalities: surgical and pharmacological. Physiotherapy along with pharmacology has shown good results in the treatment of oral sub-mucous fibrosis. Physiotherapy management includes excercises which has proven to have a great impact on treatment of oral submucous fibrosis..$^{7-9}$

Various exercises for oral submucous fibrosis patients

The various exercises which may be prescribed are:

1. Tongue blade exercise

2. Tongue-in-Cheek Push

3. Side Tongue Stretch

4. Cheek Puff

5. Pucker

6. "O" Exercise

7. Lip Hold

8. Up and Down Tongue Stretch

9. Teeth Sweep

\section{Tounge blade exercise}

Stick your tongue out straight. Press your tongue tip out against a flat wooden stick or tongue blade 2 or 3 times.
Now press the stick in while you push your tongue tip out against the stick. Hold this for 10 seconds.

Put the stick against one side of your tongue. Push the side of your tongue against the stick while you push the stick in. Hold for 10 seconds.

Repeat on the other side of your tongue. Place the stick on top of your tongue tip. Press your tongue up against the stick as you push down on the stick. Hold for 10 seconds.

\section{Tongue-in-cheek push}

Push your tongue against the inside of your right cheek and move it up and down. Repeat this 10 times. Now do the same on the left cheek. Push your tongue against the inside of your right cheek. Put your finger on the outside of your cheek and push back against your tongue. Hold for 5 seconds. Now do the same on the left cheek.

\section{Side tongue stretch}

Stick your tongue out to the right side of your mouth. Stretch it to the right as far as you can for 10 seconds. Stick your tongue out the left side of your mouth. Stretch it to the left as far as you can and hold it for 10 seconds. Stick your tongue out and move it quickly from side to side, being sure to touch the corner of your mouth on each side each time.

\section{Cheek puff}

Take in a deep breath and puff your cheeks out. Hold the air in your cheeks by tightly closing your lips together. Hold the air in your cheeks for 5 seconds. Take in another deep breath and only hold air in your left cheek. Then switch and hold air only in your right cheek.

\section{Pucker}

Pucker your lips like you are going to give someone a kiss. Hold for 5 seconds. Pucker your lips and move your pucker from one side to the other. Do not move your tongue. Repeat this 10 times. Close you lips tightly and say "m, m, $\mathrm{m} "$, then "p, p, p", then "b, b, b". For more lip closure practice, say "me, me, me", "pe, pe, pe", "be, be, be". 


\section{"O" Exercise}

Start with your jaw wide open and hide your teeth under your lips. Purse your lips in an "O" shape. Repeat this 10 times.

\section{Lip hold}

Put a small flat stick or tongue blade between your lips. Press only with your lips and hold the stick straight out from your mouth. Hold the stick for 1 minute, or as long as you can.

\section{Up and down tongue stretch}

Open your mouth and stick your tongue out and down toward your chin. Stretch your tongue down and hold for 10 seconds. Open your mouth and stick your tongue up toward your nose. Stretch your tongue up and hold for 10 seconds.

\section{Teeth sweep}

Touch the tip of your tongue to the biting surface of your upper front teeth. Slide your tongue tip along your tooth line to the far right and hold for 5 seconds. Then slide your tongue along your toothline to the far left and hold for 5 seconds. Now repeat along the biting surfaces of your bottom teeth. ${ }^{10}$

\section{Conclusion}

Although the primary care of oral submucous fibrosis is dental, the role of physiotherapy is important too. Since the action of opening of the mouth is restricted, the usage of physiotherapy has a significant impact. These simple exercises may be performed anywhere. However, if the fibrosis is extensive, it may be difficult to perform these exercises completely. Most importantly the habit of areca nut consumption needs to be reduced.

\section{Source of funding}

None.

Conflict of interest

None.

\section{References}

1. Pindborg J, Sirsat S. Oral submucous fibrosis. Oral Surg, Oral Med, Oral Pathol 1966;22(6):764.

2. Cox SC, Walker DM. Oral submucous fibrosis. A review. Aust Dent J 1996;41(5):294-9.

3. Harvey W, Scutt A, Meghji S, Canniff J P. Stimulation of human Buccal mucosa fibroblasts in vitro by areca nut alkaloids. Arch Oral Boil 1986;31:45-9.

4. Maher R, Lee A J, Warnakulasuriya KA, Lewis JA. Role of areca nut in the causation of oral submucous fibrosis: a case control study in Pakistan. J Oral Pathol Med 1994;23:65-9.

5. Canniff JP, Harvey W, Harris M. Oral submucous fibrosis: Its pathogenesis and management. Br Dent J 1986;160:429-34.

6. Tilakaratne WM, Klinikowski MF, Saku T, Peters TJ, Waranakulasuriya S. Oral submucous fibrosis: Review on aetiology and pathogenesis. Oral Oncol 2006;42:561-8.

7. Stephen Cox, Hans Zoellner. Physiotherapy treatment improves oral opening in oral submucous fibrosis. $\mathrm{J}$ Oral Pathol Med 2009;38:220-6.

8. Nidhi Thakur, Vaishali Keluskar, Anjana Bagewadi. Effectiveness of micronutrients and physiotherapy in the management of oral submucus fibrosis. Int J Contem Dent 2011;1:101-5.

9. Richa Dhariwal, Sanjit Mukherjee, Sweta Pattanayak. Zinc and Vitamin A can minimise the severity of oral submucous fibrosis. BMJ 2010;7:23-9.

10. Health Information, 2013 - May 5.

How to cite this article: Hassan SA, Bhateja S. Role of physiotherapy in oral submucous fibrosis. J Soc Indian Physiother 2020;4(1):1-2. 